\title{
Efemérides da morte de figuras públicas na imprensa: o tempo como cabide noticioso
}

\author{
Joana Martins \\ ESE, CI\&DEI, Instituto Politécnico de Viseu, Portugal - jmartins@esev.ipv.pt
}

\begin{abstract}
Resumo
A morte engloba vários ritos e rituais, entre os quais se incluem a conservação da memória do falecido. Olhando para os meios de comunicação como espaços que podem potenciar essa mesma memória, com base na ideia de cabide noticioso defendida por Nelson Traquina (2002), propusemo-nos analisar a cobertura dos aniversários da morte de 20 figuras públicas portuguesas nos jornais Correio da Manhã, Diário de Notícias e Jornal de Notícias, falecidas entre os anos de 1970 e 2014 . A análise das diferenças editoriais em relação a estas efemérides mostrou que nem sempre o

pública é o elemento que espoleta a recordação, na medida em que, por vezes, há um acontecimento paralelo que coincide com o aniversário da morte e que ancora a abordagem do jornal, levando a diferentes enquadramentos da efeméride. Fazendo um paralelismo com a obra de Fernando Catroga (1999), concluímos, pois, que a comemoração da morte visa, em alguns casos, recordar a personalidade falecida, mas em determinadas circunstâncias dá mais importância ao gancho da atualidade e à reintrodução do acontecimento em termos do seu significado na vida presente e futura.
\end{abstract} aniversário da morte de determinada figura

Palavras-chave: morte, efemérides, memória, jornalismo.

\section{Ephemeris of the death of public figures in the press: time as a news peg}

\begin{abstract}
Death encompasses several rites and rituals, including the preservation of the deceased's memory. Pondering media as spaces that can enhance this memory, and grounded on the idea of time as a news peg held by Nelson Traquina (2002), we proposed to analyze the coverage of the anniversaries of the death of 20 Portuguese public figures, who died between

1970 and 2014, in the newspapers Correio da Manhã, Diário de Notícias and Jornal de Notícias. The analysis of editorial differences in relation to these events showed that the death of a certain public figure is not always the element that triggers the memory, as, sometimes, there is a parallel event that coincides with the anniversary of the death and that
\end{abstract}

(C) do(s) Autor(s) 2021. Artigo publicado online, em acesso aberto, por Interações: Sociedade e as Novas Modernidades, ISSN: 2184-3929, em https://interacoes-ismt.com, nos termos da Licença Internacional Creative Commons Attribuiçao-NãoCommercial 4.0 (https://creativecommons.org/ 
Efemérides da morte de figuras públicas na imprensa:

o tempo como cabide noticioso

anchors the newspaper's approach, leading to a different frame of the ephemeris. In parallel with the work of Fernando Catroga (1999), we conclude, therefore, that the commemoration of death aims, in some cases, to remember the deceased personality, but in certain circumstances it gives more importance to current news and to the reintroduction of that event in terms of its meaning in the present and future life.

Keywords: death, ephemeris, memory, journalism.

\section{MORTE: RITOS E RITUAIS}

Compreender a morte é também analisar e olhar de perto os seus ritos e rituais, sobretudo aqueles que se prendem com a conservação da memória. No momento em que se prepara a eliminação do corpo do mundo dos vivos, existem várias formas de eternizar a memória dos que o habitaram, entre um povo, no caso de personalidades de destaque, ou entre os seus entes queridos, no caso da perda de alguém que nos é próximo. Existem também diferentes vivências e experiência que resultam da posição que ocupa na nossa vida a pessoa que morre.

"Ao invés de muitas ideias filosóficas e religiosas, a morte afecta cada um de nós à medida que deparamos com a morte daqueles que amamos, daqueles de quem gostamos, dos famosos que nos servem de amigos imaginários, dos nossos vizinhos e daqueles que odiamos" (Davies, 2005, p.25).

Nesta perspetiva, procuraremos compreender algumas das relações, ritos e rituais que têm a morte como pano de fundo e os media como intermediários ou, até, potenciadores da memória.

Importa, antes de mais, fazer a distinção entre estes dois conceitos: rito e ritual. Segundo Rivière, o rito tem uma inspiração de ordem religiosa e representa "um conjunto de actos repetitivos e codificados, por vezes solenes, de ordem verbal, gestual ou de postura, com forte carga simbólica", que estão ancorados na convicção de que existem seres ou poderes sagrados, "com os quais o homem tenta comunicar visando obter um determinado efeito" (2011, p.154). O ritual traduz-se no "conjunto de preceitos a observar na execução de um rito, tornando-se num esquema que se repete de forma mais ou menos imutável" (Maia, 2002, p.328). No fundo, trata-se 
de um conjunto de regras e procedimentos, consagradas por tradições, costumes ou normas, que integram um determinado acontecimento ou ato solene. $\mathrm{O}$ rito seria a cerimónia e o ritual o conjunto de comportamentos e procedimentos que a integra.

Antropólogos e sociólogos, entre os quais Arnold Van Gennep (1909), Malinowsky (1948), Norbert Elias (1987) ou Victor Turner (1974) estudaram os ritos de passagem, considerando a vida do homem como uma sucessão de estádios naturais com inícios e finais semelhantes: nascimento, puberdade, casamento, parentalidade, ascensão social, ocupação profissional especializada e morte. Para cada um destes estádios há cerimónias, cujo propósito é permitir ao indivíduo passar de uma posição definida para outra igualmente bem definida. São "ritos que acompanham toda a mudança de lugar, estado, posição social e idade" (Turner, 1974, p.116), ou seja, falamos de um conjunto de comportamentos e rituais, contidos no rito, que assinalam uma mudança de status.

No caso dos ritos funerários, segundo o antropólogo Van Gennep (1909), o período de transição é marcado de forma física, numa primeira fase, com a presença do corpo na casa do falecido, seguindo-se depois o sepulcro. Hoje em dia, este ritual tem equivalência ao velório, ou missa de corpo presente, que antecede o enterro propriamente dito. Mas o autor lembra que, para outros povos, este período de transição é sistematizado nas "comemorações" da semana, mês ou ano da morte. Estas celebrações têm paralelo com a natureza dos ritos de aniversário do casamento ou do nascimento. Atualmente, as efemérides da morte continuam a ser marcantes para as sociedades, que assinalam assim a perda dos seus entes queridos e os tornam presentes através da memória.

Do ponto de vista da memória, a necrópole é o espaço simbólico para recordar os falecidos. Catroga (1999) descreve os cemitérios como espaços públicos e afetivos, numa lógica de memória do indivíduo, mas também numa perspetiva de espaço de confronto entre a morte como finitude humana e o sonho utópico de superação do transcurso do tempo.

O autor entende a memória como re-presentificação, ou seja, metamemória, entendida esta última como o conjunto de "representações que cada indivíduo faz da sua própria memória, o conhecimento que tem desse facto, e o que afirma sobre isso". Segundo o historiador, todas estas são "dimensões que remetem para a maneira como cada um se filia no seu próprio passado e constrói a sua identidade" (Catroga, 1999, p.13), ou seja, são as recordações e imagens do indivíduo, baseadas na leitura atual que ele faz do que foi o seu passado. É esta memória que está inter-relacionada 
Efemérides da morte de figuras públicas na imprensa:

o tempo como cabide noticioso

com a existência dos mortos. "De facto, se ontologicamente a morte remete para o não-ser, é na memória dos vivos, enquanto imagens suscitadas a partir de traços com referente, que os mortos poderão ter existência (mnésica)" (Catroga, 1999, p.14). Neste contexto, o autor considera que as necrópoles ocidentais congregam signos e símbolos "dissimuladores do sem-sentido da morte e simuladores da somatização do cadáver". Para Catroga o cemitério é, pois, um campo simbólico de memória, que encobre aquilo que se pretende esquecer e recusar. "Perante a incompreensabilidade do morrer, a memória emerge como protesto compensatório", diz o autor, lembrando que cada um se antevê na morte do outro e que ao recordar o finado o homem está, ainda que de forma inconsciente, a projetar a sua futura morte (Catroga, 1999, p.15). Os símbolos funerários visam, assim, edificar memórias e representar o ausente, ao mesmo tempo que congregam um certo nível de amnésia face àquilo que se quer esquecer: a própria morte.

Fernando Catroga destaca os novos ritos dos cemitérios, assentes nas visitas periódicas (com maior ênfase no Dia dos Defuntos) aos entes queridos dos vivos. Este será um rito de recordação comemorativo, ainda que o autor estabeleça uma diferença entre a recordação como ato individual e a comemoração como manifestação de alteridade. Aqui, a recordação é lida como "uma re-suscitação de acontecimentos do passado, a propósito de aniversários colectivos ou individuais, com a virulência vivificante que teriam quando foram presente". A comemoração visa não só recordar, mas também reintroduzir o acontecimento na vida presente e nas expetativas de futuro. Para o autor, esta visita ao cemitério é um dos ritos comemorativos e incorpora determinados comportamentos-tipo, como a deposição de flores e o respeito do silêncio no cemitério. A corporização destes comportamentos é quase sempre coletiva e pública (Catroga diz que as visitas individuais são exceção) e visa recordar o morto, bem como reforçar o cosmos dos vivos. Nestes casos estamos perante a "memória reavivada pelo rito", ou seja, uma reconstrução de um eu coletivo, identidade gerada pela memória, que assenta numa seleção do passado, incluindo o recalcamento do que se pretende esquecer (Catroga, 1999, pp. 23-24).

\section{O TEMPO COMO CABIDE NOTICIOSO NOS MEDIA}

Os valores-notícias, ou critérios de noticiabilidade, continuam a ser importantes para justificar a presença de alguns temas, e não de outros, no espectro da comuni- 
cação social. Partindo da ideia da noticiabilidade como a aptidão que cada acontecimento possui para se tornar notícia (Wolf, 2009), existem múltiplas propostas de critérios, defendidas por diferentes autores, que mostram como a seleção de acontecimentos depende de diversos, e por vezes subjetivos, fatores, pontos de vista e critérios organizacionais.

Um desses autores é Nelson Traquina (2002), para quem os valores-notícia se dividem em critérios de seleção (aplicados no momento em que o editor decide transformar ou não um acontecimento em notícia) e critérios de construção (qualidades da notícia que se tornam evidentes durante a sua construção e que ajudam a decidir o que realçar e o que omitir). Entre os valores-notícia de seleção está o critério de tempo que, segundo Traquina, pode ser entendido como atualidade, como cabide e ainda como extensão do acontecimento. Quanto à ideia de cabide, ou news peg, o autor refere-se especificamente às efemérides e explica que "o próprio tempo (a data específica) pode servir como um news peg e justificar a noticiabilidade de um acontecimento que já teve lugar no passado, mas nesse mesmo dia". Traquina dá o exemplo dos aniversários, salientando que, nestes casos, se faz notícia sobre a morte de alguém que aconteceu "neste mesmo dia há x anos", o que significa que "o próprio fator tempo é utilizado como gancho para justificar falar de novo sobre esse assunto" (Traquina, 2002, pp. 189-190).

\section{METODOLOGIA}

É objetivo desta investigação perceber quais as opções editoriais de três jornais portugueses, no tratamento da morte de figuras públicas, especificamente no que diz respeito às efemérides do seu falecimento. Optámos, assim, por uma análise quantitativa do conteúdo das edições do Correio da Manhã, do Jornal de Notícias e do Diário de Notícias, no âmbito do tratamento noticioso que fizeram quando do falecimento de António de Oliveira Salazar, Fernando Pascoal das Neves (Pavão), Francisco Sá Carneiro, Joaquim Agostinho, António Variações, Zeca Afonso, Carlos Paião, Miguel Torga, Beatriz Costa, António de Spínola, Vítor Batista, Amália Rodrigues, Sophia de Mello Breyner, Álvaro Cunhal, José Megre, Raul Solnado, José Saramago, António Feio, Angélico Vieira e Eusébio da Silva Ferreira. Os períodos temporais analisados das efemérides destas mortes são: um mês, seis meses, um ano, dez anos e 20 anos. Esta opção é consonante com a ideia de Arnold Van Gennep (1909: p.214), 
Efemérides da morte de figuras públicas na imprensa:

o tempo como cabide noticioso

ao considerar que a extensão do período que marca o regresso dos enlutados ao seio da sociedade pode ser sistematizada nas efemérides assinaladas.

Escolhemos casos de figuras públicas desaparecidas, de reconhecida relevância nas suas áreas de intervenção social, mediados pelos 44 anos que vão, desde a morte de Salazar, em 1970, ao falecimento de Eusébio, em 2014. O estudo integra várias personalidades que faleceram em idades diferentes e com distintos reconhecimentos públicos (algumas já consagradas, outras com um promissor futuro por cumprir). Falamos, pois, de personalidades diversas, com histórias diferentes, quer do ponto de vista da idade com que morreram, quer ainda da proeminência e do reconhecimento público que detinham nas suas diferentes áreas de intervenção social. Considerando os segmentos mais representativos da sociedade do espetáculo (política, arte e desporto), procurámos integrar um número equilibrado de figuras públicas em cada uma das categorias.

Em relação aos jornais escolhidos, e face ao período temporal que estará em análise, só poderíamos optar por jornais diários generalistas. No que diz respeito ao intervalo de tempo englobado - 1970 a 2014 - os únicos jornais que foram publicados durante todo este período foram o Diário de Notícias e o Jornal de Notícias. No entanto, pareceu-nos que deveríamos acrescentar um terceiro título, até porque os dois periódicos mencionados passaram a integrar a mesma empresa (Global Media Group) no início dos anos 90. Assim, optámos pelo Correio da Manhã, que só começou a ser publicado em 1980, mas era o diário generalista que melhor podia cobrir o período temporal da nossa investigação. Para além disso, falamos do jornal português com caraterísticas tipicamente populares, o que acrescenta uma dimensão importante à nossa investigação, alargando o espetro da tipologia de periódicos em análise, desde o jornalismo de referência ao jornalismo assumidamente popular. Com a escolha do Correio da Manhã, apenas as efemérides de um mês, seis meses e um ano da morte de Salazar e de Pavão ficaram por analisar.

$\mathrm{Na}$ análise quantitativa decidimos contabilizar o número de páginas de cada edição em que a personalidade é referenciada, o número de peças publicadas e as imagens respeitantes a essas mesmas peças. Contabilizámos também os destaques nas capas dos jornais e as fotografias existentes nessas primeiras páginas. Seguidamente procedemos à distinção dos géneros jornalísticos de cada uma das peças e analisámos o tema em destaque no conteúdo de cada peça. 


\section{RESULTADOS}

A partir da análise da cobertura da morte de 20 figuras públicas portuguesas, entre os anos de 1970 e 2014, nos jornais Correio da Manhã, Diário de Notícias e Jornal de Notícias, sistematizámos as efemérides do falecimento das personalidades na grelha de análise (tabela 1$)$.

\section{Tabela 1}

Número de páginas, peças, imagens e destaques de capa que assinalam as efemérides da morte das personalidades

\begin{tabular}{|c|c|c|c|c|c|}
\hline Personalidades & $\begin{array}{c}\text { Número } \\
\text { de } \\
\text { páginas }\end{array}$ & $\begin{array}{l}\text { Número } \\
\text { de peças }\end{array}$ & $\begin{array}{c}\text { Número } \\
\text { de } \\
\text { imagens }\end{array}$ & $\begin{array}{c}\text { Número } \\
\text { de } \\
\text { destaques } \\
\text { em capa }\end{array}$ & Total \\
\hline Álvaro Cunhal & 10 & 8 & 20 & 2 & 40 \\
\hline Amália Rodrigues & 14 & 30 & 32 & 3 & 79 \\
\hline Angélico Vieira & 1 & 1 & 1 & 0 & 3 \\
\hline António de Oliveira Salazar & 5 & 4 & 2 & 1 & 12 \\
\hline António de Spínola & 1 & 1 & 1 & 0 & 3 \\
\hline António Feio & 1 & 2 & 3 & 0 & 6 \\
\hline António Variações & 6 & 4 & 3 & 1 & 14 \\
\hline Beatriz Costa & 0 & 0 & 0 & 0 & 0 \\
\hline Carlos Paião & 1 & 1 & 1 & 0 & 3 \\
\hline Eusébio & 5 & 9 & 8 & 1 & 23 \\
\hline $\begin{array}{l}\text { Fernando Pascoal das Neves } \\
\text { "Pavão" }\end{array}$ & 2 & 2 & 0 & 0 & 4 \\
\hline Francisco Sá Carneiro & 38 & 47 & 41 & 10 & 136 \\
\hline Joaquim Agostinho & 11 & 15 & 16 & 1 & 43 \\
\hline José Afonso & 13 & 32 & 28 & 3 & 76 \\
\hline José Megre & 0 & 0 & 0 & 0 & 0 \\
\hline José Saramago & 5 & 8 & 6 & 0 & 19 \\
\hline Miguel Torga & 9 & 13 & 8 & 1 & 31 \\
\hline Raul Solnado & 1 & 1 & 1 & 0 & 3 \\
\hline Sophia de Mello Breyner & 3 & 3 & 3 & 0 & 11 \\
\hline Vítor Batista & 0 & 0 & 0 & 0 & 0 \\
\hline
\end{tabular}

Fonte: Elaboração própria 
Efemérides da morte de figuras públicas na imprensa:

o tempo como cabide noticioso

Da análise da tabela sobressaem os casos em que as efemérides não foram de todo assinaladas (Beatriz Costa, José Megre e Vítor Batista) e, pelo contrário, os casos em que os jornais recordaram de forma intensa as personalidades já falecidas (Francisco Sá Carneiro, Amália Rodrigues e José Afonso).

Atentando no número de efemérides que foram capa dos jornais analisados, percebemos que a recordação da morte de Sá Carneiro foi o assunto que mereceu mais chamadas de primeira página. Este dado está relacionado com as consequências do acidente que vitimou o então primeiro-ministro, bem como com as causas nunca determinadas desse mesmo acidente.

Podemos considerar apenas o número total de notícias, discriminando os dados por jornal (tabela 2). Percebemos, pois, algumas diferenças em termos de opções editoriais, desde logo, porque o Diário de Notícias é o jornal que assinala o maior número de efemérides e o Correio da Manhã é o título com o menor número de peças publicadas.

Já no que diz respeito aos géneros jornalísticos, o Gráfico 1 mostra-nos uma preponderância de notícias breves e de notícias desenvolvidas. Ainda assim, não podemos deixar de considerar que os géneros de opinião (artigo, crónica e editorial), também são convocados para a cobertura das efemérides da morte das personalidades, assim como as biografias, que reconstroem a vida e o percurso da figura pública.

\section{Gráfico 1}

Número de peças, por género jornalístico, na cobertura das efemérides
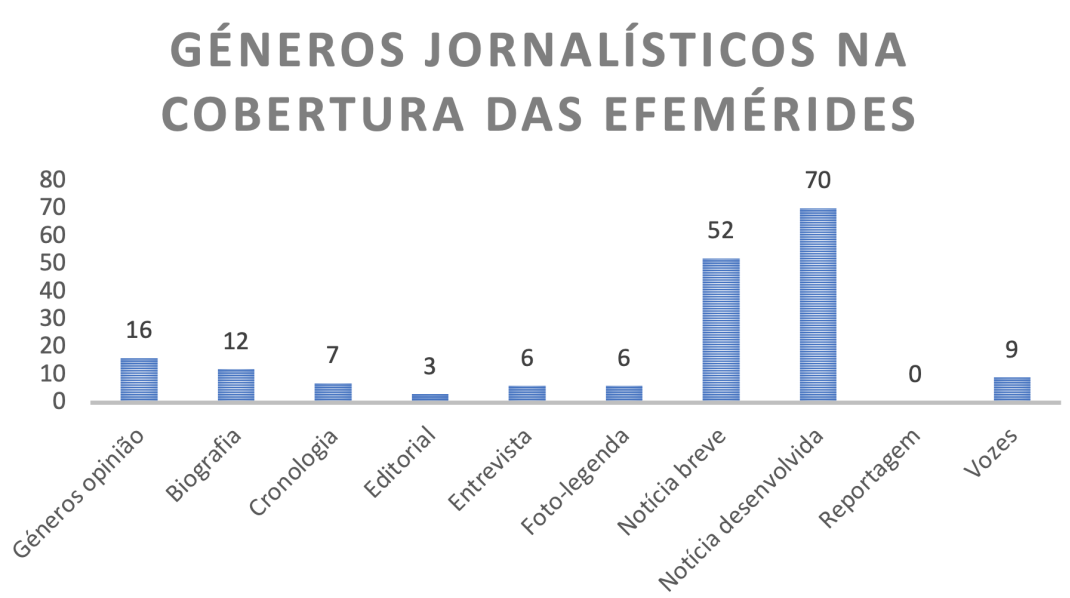

Fonte: Elaboração própria. 
Tabela 2

Número de peças jornalísticas que assinalam as efemérides da morte das personalidades

\begin{tabular}{|c|c|c|c|c|}
\hline Personalidade & $\begin{array}{l}\text { Total de peças } \\
\text { nas datas das } \\
\text { efemérides }\end{array}$ & $\begin{array}{l}\text { Total de peças } \\
\text { nas datas das } \\
\text { efemérides } \\
\text { no Correio da } \\
\text { Manhã }\end{array}$ & $\begin{array}{l}\text { Total de peças } \\
\text { nas datas das } \\
\text { efemérides } \\
\text { no Diário de } \\
\text { Notícias }\end{array}$ & $\begin{array}{c}\text { Total de peças } \\
\text { nas datas das } \\
\text { efemérides } \\
\text { no Jornal de } \\
\text { Notícias }\end{array}$ \\
\hline Álvaro Cunhal & 8 & 1 & 6 & 1 \\
\hline Amália Rodrigues & 30 & 12 & 7 & 11 \\
\hline Angélico Vieira & 1 & 1 & 0 & 0 \\
\hline $\begin{array}{l}\text { António de Oliveira } \\
\text { Salazar }\end{array}$ & 4 & 0 & 2 & 2 \\
\hline António de Spínola & 1 & 1 & 0 & 0 \\
\hline António Feio & 2 & 2 & 0 & 0 \\
\hline António Variações & 4 & 1 & 2 & 1 \\
\hline Beatriz Costa & 0 & 0 & 0 & 0 \\
\hline Carlos Paião & 1 & 1 & 0 & 0 \\
\hline Eusébio & 9 & 1 & 3 & 5 \\
\hline $\begin{array}{l}\text { Fernando pascoal das } \\
\text { neves "Pavão" }\end{array}$ & 2 & 1 & 0 & 1 \\
\hline Francisco Sá Carneiro & 47 & 7 & 23 & 17 \\
\hline Joaquim Agostinho & 15 & 2 & 10 & 3 \\
\hline José Afonso & 32 & 14 & 12 & 6 \\
\hline José Megre & 0 & 0 & 0 & 0 \\
\hline José Saramago & 8 & 1 & 3 & 4 \\
\hline Miguel Torga & 13 & 2 & 5 & 6 \\
\hline Raul Solnado & 1 & 1 & 0 & 0 \\
\hline Sophia de mello breyner & 3 & 1 & 1 & 1 \\
\hline Vítor Baptista & 0 & 0 & 0 & 0 \\
\hline TOTAL & 183 & 49 & 75 & 59 \\
\hline
\end{tabular}

Fonte: Elaboração própria. 
Efemérides da morte de figuras públicas na imprensa:

o tempo como cabide noticioso

\section{A EFEMÉRIDE COMO CABIDE E COMO COMEMORAÇÃO}

Tendo em consideração os dados quantitativos, e tal como já foi referido, percebemos que as personalidades mais recordadas (em texto e em imagem) em efemérides foram Francisco Sá Carneiro, José Afonso e Amália Rodrigues. Em sentido contrário, Beatriz Costa, José Megre e Vítor Batista não foram alvo de qualquer notícia nos aniversários das suas mortes. O Diário de Notícias foi o jornal que dedicou mais espaço a estas notícias, seguido do Jornal de Notícias e do Correio da Manhã. As notícias breves, notícias desenvolvidas, opinião e biografias foram os géneros mais utilizados nas peças.

A análise do conteúdo das notícias suscitou outras conclusões, desde logo quanto ao tipo de efeméride e à sua motivação. A primeira conclusão mostra que a efeméride de seis meses nunca foi assinalada. Aliás, no dia em que se completavam seis meses após a morte de Francisco Sá Carneiro, coincidentemente, os filhos do primeiro-ministro falecido haviam recusado, na véspera, a condecoração que seria atribuída ao pai. Assim, as notícias surgem na edição daquele dia, mas nenhuma evoca os seis meses decorridos sobre a morte de Sá Carneiro.

A segunda e mais importante conclusão colocou-nos perante dois tipos de efemérides: aquelas em que o aniversário da morte da personalidade é o acontecimento central; e aquelas em que há um acontecimento atual que ganha protagonismo, relegando a recordação da morte para segundo plano. No primeiro caso falamos das verdadeiras efemérides mediáticas, aqui entendidas como aquelas em que o aniversário da morte é o cabide noticioso. São notícias que simplesmente evocam a personalidade falecida, tendo por base uma opção editorial e não agendamentos exteriores. É o que acontece nos dez anos e nos vinte anos após o falecimento de Joaquim Agostinho, em que o Correio da Manhã, o Diário de Notícias e o Jornal de Notícias recordam o ciclista, a sua carreira e as circunstâncias da sua morte. O mesmo se verifica no primeiro aniversário da morte de Carlos Paião, por parte do Correio da Manhã, e no primeiro ano após o falecimento de Amália Rodrigues no Correio da Manhã, Diário de Notícias e Jornal de Notícias. O mesmo se pode dizer da morte de Álvaro Cunhal, pois na passagem da primeira década sobre o acontecimento, o histórico líder comunista motivou a foto de capa do Diário de Notícias e uma entrevista de quatro páginas a Pacheco Pereira, seu biógrafo, sem nenhum outro acontecimento externo que motivasse a memória do jornal. 
Ainda de destacar os 20 anos após a morte de José Afonso. Apesar de estarem agendadas iniciativas para esse dia, nenhum dos jornais colocou o enfoque nessas homenagens. Curiosamente o ângulo foi o mesmo nos três diários: o olhar sobre os músicos das novas gerações e o legado que José Afonso representava para cada um deles. É um exemplo de como a efeméride pode ser explorada e amplificada, tendo por base não a memória diferida por um qualquer cabide noticioso oficial, mas pela agenda autónoma dos media, que julga a efeméride como um facto suficiente para se constituir como notícia. A exposição inaugurada aquando dos dez anos da morte de Amália Rodrigues também deu o mote para que os três jornais recordassem a fadista, mas todos foram mais longe e abriram a amplitude do tema, evocando a cantora e convocando articulistas para a recordarem. O facto, aliás, de o acontecimento ser foto de capa no Jornal de Notícias explica bem a relevância de Amália, mesmo dez anos após a sua morte.

Por outro lado, é possível identificar casos em que a efeméride não existe com esse propósito e em que não há uma estratégia do jornal para recordar a personalidade falecida. Em alguns desses casos, o tempo como atualidade sobrepôs-se à ideia do cabide noticioso. No dia em que se completaram dez anos da morte de Sophia de Mello Breyner Andresen os jornais publicaram uma breve sobre a trasladação do corpo da poetisa para o Panteão Nacional, que teria lugar nesse mesmo dia. O foco das notícias foi a transferência dos restos mortais da escritora e nenhum dos jornais aproveitou a ocasião para recordar o seu trajeto. Nestes casos não é o jornal que traz à memória do público alguém que já faleceu, é a própria realidade que se impõe ao jornal, que, por sua vez, pode nem evocar a personalidade, mas sim centrar-se nos factos que ajudaram a trazê-la à lembrança. O facto de os restos mortais de Sophia serem trasladados para o Panteão Nacional marcaram a agenda noticiosa do $100^{\circ}$ aniversário da sua morte, pelo que a memória dos media é diferida por um acontecimento externo que condiciona as suas escolhas.

Concomitantemente, aquando da primeira década após a morte de Francisco Sá Carneiro, havia sido inaugurada, na véspera, a nova aerogare no Porto, à qual foi dado o nome do ex-primeiro-ministro. Esta inauguração deu o mote para a efeméride, mas, ainda assim, foi possível identificar diferenças de tratamento editorial entre os jornais analisados. Se, por exemplo, o Correio da Manhã não aproveita o acontecimento para recordar o político, o Diário de Notícias relega a inauguração para segundo plano e foca o seu conteúdo noticioso na evocação da personalidade, enquadran- 
Efemérides da morte de figuras públicas na imprensa:

o tempo como cabide noticioso

do novamente a falta de conclusões em torno do acidente que vitimou Sá Carneiro.

Também o programa de homenagens dedicado a Miguel Torga, e anunciado aquando dos dez anos sobre a sua morte, justificam grande parte dos conteúdos escritos pelo Diário e Notícias e Jornal de Notícias, ainda que os dois diários aproveitem para recordar o escritor. O primeiro ano após a morte de José Saramago também foi ancorado nas homenagens que visavam assinalar a data. O mesmo se verifica nos 20 anos após a morte de António Variações: a propósito da intenção da EMI-Valentim de Carvalho em lançar um álbum de homenagem ao cantor, o Correio da Manhã aproveita para fazer a sua biografia e fala na doença que o vitimou, a Sida.

A propósito das visitas periódicas aos cemitérios, Fernando Catroga (1999) destaca a importância da recordação como forma de ressuscitar acontecimentos do passado, sobretudo quando falamos de aniversários coletivos (Dia de Todos os Santos) ou individuais. No caso das efemérides das personalidades que fizeram parte deste estudo, percebemos que, tal como diz Catroga, muitas vezes a comemoração da data, além de recordar a pessoa, visa também reintroduzir o acontecimento na vida presente e nas expetativas de futuro, em consonância também com a ideia de cabide noticioso. Assim, foi possível identificar dois posicionamentos editoriais: os casos em que o acontecimento "aniversário da morte" é suficiente para justificar o cabide noticioso; e os casos em que há um acontecimento paralelo no dia da efeméride, que é assumido como principal ângulo de abordagem pelo jornal, relegando o aniversário da morte para segundo plano.

\section{CONCLUSÃO}

Foi nosso objetivo tentar perceber o processo e o papel dos jornais na inscrição da memória pública, procurando assim verificar se e como eram recordadas as datas comemorativas da morte das personalidades em estudo. A esta temporalidade esteve subjacente a ideia de cabide noticioso como valor-notícia (Traquina, 2002), uma vez que, como já vimos, o tempo pode ser pretexto para determinadas notícias, como é o caso dos aniversários da morte de figuras públicas.

Revisitámos este acontecimento em datas marcantes - um mês, seis meses, um ano, dez anos e 20 anos - de modo a perceber a forma como as pessoas continuam ou passaram a ser recordadas, acompanhando, em simultâneo, eventuais transformações narrativas dos jornais analisados, em função da alteração do ecossistema mediá- 
tico ao longo dos anos. Para além disso, o alargamento do espaço temporal de análise pode também ser revelador sobre a força e autonomia das figuras consideradas, nomeadamente quanto à sua capacidade de se imporem como uma narrativa de vida que se sobrepõe aos constrangimentos momentâneos da cobertura jornalística ou aos sentimentos controversos e/ou contraditórios das opiniões (pública e publicada).

A morte é, em si mesma, um valor-notícia, seja em nome próprio (Traquina, 2002), ou enquanto expressão da negatividade (Galtung e Ruge, 1965; Harcup e O’Neill, 2017; Wolf, 2009). No caso da morte de figuras públicas, é preciso considerar que está presente, também, a proeminência social como critério de noticiabilidade. Adicionando o fator tempo enquanto cabide noticioso, seria expectável encontrar expressão editorial dos aniversários da morte das figuras públicas, ainda que os graus de notoriedade sejam diferentes entre elas.

Quando procuramos compreender a escolha dos acontecimentos que efetivamente são transformados em notícia, devemos ainda considerar outros aspetos, do ponto de vista organizacional das redações. No âmbito da Teoria Organizacional, a questão do enquadramento é particularmente relevante, sobretudo se tivermos em consideração, tal como refere Gaye Tuchman (1978), que ao fabricarem notícias os jornalistas também enquadram os acontecimentos. O enquadramento significa, por isso, que há elementos que são excluídos e outros que são incluídos no conteúdo da mensagem informativa, até porque as escolhas do jornalista na construção da notícia são uma forma de organizar o acontecimento, procurando dar-lhe sentido.

Este estudo mostrou que nem todos os aniversários da morte das figuras públicas foram assinalados, o que indica a existência de diferenças, em termos de proeminência, entre cada personalidade e, ao mesmo tempo, sublinha a ideia de que um acontecimento não representa apenas um, mas sim múltiplos valores-notícias conjugados (Wolf, 2009). A combinação de diferentes critérios, no caso das efemérides, seria o fator tempo, a morte e a notoriedade. Ainda assim, falamos de acontecimentos que já perderam atualidade e que, em alguns casos, precisam do fator novidade para ancorar a recordação da data.

Por outro lado, e tendo em consideração as questões relacionadas com o enquadramento, faz sentido recuperar a metáfora da janela utilizada por Gaye Tuchman, para quem "a notícia é uma janela para o mundo" (Tuchman, 1983, p. 13). Segundo a autora, a visão de cada meio de comunicação social depende do tamanho da sua janela, do número de janelas disponíveis, da opacidade dos seus vidros e do sítio para onde essa janela está virada. De acordo com esta metáfora, os jornalistas olham para 
Efemérides da morte de figuras públicas na imprensa:

o tempo como cabide noticioso

o mundo através das suas janelas e é somente aquilo que veem através delas que pode integrar as notícias.

Nesse sentido, identificámos dois cenários que expressam diferentes opções editoriais, que podem ser explicadas por diferentes critérios de noticiabilidade ou, até, por um diferente enquadramento dos acontecimentos. Por um lado, em casos como o de Álvaro Cunhal, Amália Rodrigues, Joaquim Agostinho ou José Afonso, o aniversário das suas mortes foi um cabide suficientemente forte para "pendurar" a notícia 10 anos depois e o enquadramento foi a recordação destas personalidades. Por outro lado, acontecimentos como a trasladação de Sophia de Mello Breyner, as homenagens a Miguel Torga e José Saramago ou a inauguração do aeroporto Francisco Sá Carneiro, foram assumidos como ângulos de abordagem ancorados na atualidade e até no futuro (no caso do acidente de Camarate que estava ainda por resolver). Nestes casos, a janela escolhida para olhar o acontecimento não é a morte em si mesma e a lógica de recordação da personalidade passa para segundo plano.

Recuperando a ideia de Fernando Catroga, a recordação como ato individual, ou seja, a "re-suscitação de acontecimentos do passado" no aniversário da morte (Catroga, 1999, p. 23), as efemérides assinaladas tendo como único foco a recordação da personalidade falecida dispensam o fator atualidade e mostram que aquele acontecimento ainda tem força para se impor à agenda do dia. Por outro lado, a comemoração como manifestação de alteridade, ou seja, que além de recordar também pretende introduzir novamente o acontecimento na vida presente e nas expetativas de futuro, encontra eco na ideia de um novo acontecimento, com expressão presente e futura, que assume maior relevância a partir de um novo enquadramento. É a ideia de recordar o morto e, ao mesmo tempo, reforçar o cosmos dos vivos, que vai além do cabide noticioso enquanto valor-notícia: a morte, só por si, não é o gancho da efeméride, na medida em que há um acontecimento atual que conquista maior peso editorial e esse mesmo acontecimento é a janela através da qual a efeméride é construída.

\section{REFERENCIAS}

Catroga, F. (1999). O céu da memória: cemitério romântico e o culto cívico dos mortos. Minerva.

Davies, D. J. (2005). História da morte. Editorial Teorema. 
Galtung, J. e Ruge, M. H. (1965). The structure of foreign news. Journal of peace research, 2 (1), 64-91.

Harcup, T. \& O'Neill, D. (2017). What is News? Journalism Studies, 18:12, 1470-1488. https://doi.org/10.1080/1461670X.2016.1150193

Maia, R. L. (2002). Dicionário de sociologia. Porto Editora.

Rivière, C. (2011). Introdução à antropologia. Edições 70.

Traquina, N. (2002). O que é jornalismo. Quimera Editores.

Tuchman, G. (1983). La produccion de la noticia. Estudios sobre la construccion social de la realidad. Editorial Gustavo Gili.

Turner, V. (1974). O processo ritual: estrutura e antiestrutura. Editora Vozes.

Van Gennep, A. (1909). The rites of passage. In A. Robben (Ed.) Death, mourning, and burial (pp. 213-223). Blackwell Publishing.

Wolf, M. (2009). Teorias da comunicação. Editorial Presença. 